20 Brodehl J. Conventional therapy for idiopathic nephrotic syndrome. Clin Nephrol 1991; 35 (suppl 1): S8-15.

21 Lewis MA, Baildom EM, Davis N, Houston IB, Postlethwaite RJ. Nephrotic syndrome: from toddlers to Postlethwaite RJ. Nephrotic syndr

22 Koskimies O. Long term outlook of primary nephrotic syndrome. Arch Dis Child 1982; 57: 544-8.

23 International Study of Kidney Disease in Children. Early identification of frequent relapsers among children with minimal change nephrotic syndrome. $\mathcal{F}$ Pediatr 1982 ; 101 514-8.

24 Wingen AM, Müller-Wiefel DE, Schärer K. Spontaneous remission in frequently relapsing and steroid dependen idiopathic nephrotic syndrome. Clin Nephrol 1985; 23: 35-8.

25 International Study of Kidney Disease in Children Nephrotic syndrome in children. A randomised trial comparing two prednisone regimens in steroid responsive comparing two prednisone regimens in steroid responsive

26 Wingen AM, Müller-Wiefel DE, Schärer K. Comparison of different regimens of predisone in frequently relapsing different regimens of predisone in frequently relapsing nephrotic syndrome. Acta Paediatr Scand 1990; 79: 305-10
Brodehl J. Nephrotic syndrome in children. Diagnosis and treatment. World Pediatrics and Child Care 1986; 1: 9-18

28 Brocklebank JT, Harcourt RB, Meadow SR. Corticosteroid induced cataracts in idiopathic nephrotic syndrome. Arch Dis Child 1982; 53: 30-1.

29 Trompeter RS, Lloyd BS, Hicks J, White RHR, Cameron JS. Longterm outcome for children with minimal change nephrotic syndrome. Lancet 1985; i: 368-70.

30 Moxon ER. Should children with nephrotic syndrome be immunised against pneumococcal infection? Pediatr Nephrol 1991; 5: 283 .

31 Hoyer PF, Gonda S, Barthels M, Krohin HP, Brodehl J. Thromboembolic complications in children with nephrotic syndrome. Acta Paediatr Scand 1986; 75: 804-10.

32 Barratt TM, Soothill JF. Controlled trial of cyclophosphamide in steroid sensitive relapsing nephrotic syndrome of childhood. Lancet 1970; ii: 479-82.

33 International Study of Kidney Disease in Children. Prospective controlled trial of cyclophosphamide in children with nephrotic syndrome. Lancet 1974; ii: 423-7.

34 Grupe WE, Makker SP, Ingelfinger JR. Chlorambucil treatment of frequently relapsing nephrotic syndrome. $N$ Engl F Med 1976; 295: 746-9.

35 British Association for Paediatric Nephrology. Levamisole for corticosteroid dependent nephrotic syndrome in for corticosteroid dependent nephro

36 Niaudet P, Broyer M, Habib R. Treatment of idiopathic nephrotic syndrome with cyclosporin $\mathrm{A}$ in children. Clin Nephrol 1991; 35 (suppl 1): S31-6.

37 Tejani A, Suthanthiran M, Pomrantz A. A randomised controlled trial of low dose predisolone and cyclosporin versus high dose prednisolone in nephrotic syndrome of childhood. Nephron 1991; 59: 96-9.

38 Watson AR, Rance CP, Bain J. Long term effects of cyclophosphamide on testicular function. BMF 1985; 291 1457-60.

39 Watson AR, Taylor J, Rance CP, Bain J. Gonadal function in women treated with cyclosphosphamide for childhood nephrotic syndrome: a long-term follow-up study. Fertil nephrotic syndrome:
Steril 1986; 46: 331-3.

\section{Editors' comments}

We now receive consensus statements from expert panels which cannot be amended in the light of comments from the referees. These statements are not cast in stone and on this occasion our referee drew attention to the following points.

\section{Referee's comments and responses from Dr Alan Watson (convenor)}

Point 1. There is no clear guideline as to which patients can be handled by a general paediatrician and at what stage referral to a paediatric nephrologist should be considered.

Most children with nephrotic syndrome are admitted and treated under the care of general paediatricians. Children between the ages of 1 and 10 years are very likely to have steroid responsive minimal change disease and so prednisolone treatment is usually initiated without a renal biopsy. Children should be referred to a paediatric nephrology centre at the outset if they are less than 1 year of age or older than 12 years, as minimal change disease is less likely and the pathology will need to be defined. Patients should also be referred if the child has atypical features with mixed nephritic/nephrotic picture associated with macroscopic haematuria, and/or renal insufficiency or hypocomplementaemia or hypertension.

If, during the course of the initial steroid treatment complications ensue such as thrombosis, peritonitis, or acute renal failure then a paediatric nephrologist's opinion should be sought. All patients who do not respond to 28 days of daily prednisolone are classified as early steroid resistant and should be referred for consideration of renal biopsy and further management. Steroid resistance developing in subsequent prednisolone courses, steroid toxicity, and consideration of cyclophosphamide treatment also warrant discussion and possible referral to a paediatric nephrologist.

Point 2. The definition of congenital, primary, and secondary nephrotic syndromes are not clearly made. There is some confusion created between the clinical and histological categories which should be clarified.

Definitions of congenital, primary, and secondary nephrotic syndromes are beyond the remit of the paper and readers are referred to standard textbook definitions and further discussion of clinical and histological categories. $^{1}$

Point 3. The use of diuretics in an oedematous nephrotic should be expanded. It may not be wise to recommend that a general paediatrician should prescribe frusemide to a nephrotic, without prior volume expansion or discussion with a paediatric nephrologist. Attention should be drawn to the problems of spironolactone in the presence of hyperkalaemia.

The question of diuretics in the management of the oedematous nephrotic child was discussed at some length by the expert panel. It was felt that patients could be managed safely with the doses of frusemide $(1-2 \mathrm{mg} / \mathrm{kg} / \mathrm{body}$ weight/day) and spironolactone $(2 \mathrm{mg} / \mathrm{kg} /$ body weight/day) as specified so long as the children were carefully assessed for signs of hypovolaemia. Spironolactone is unlikely to result in hyperkalaemia when combined with frusemide at this dosage and when there is no renal insufficiency. The paediatric nephrologist should be consulted if the child's oedematous state becomes more troublesome as the combination of metolazone and frusemide might be suggested but this will require closer monitoring of the plasma electrolytes.

Point 4. Clearer guidance should be given on the dose of steroids that would allow live vaccines to be given safely.

Use of live vaccinations should be avoided until the child has been off daily steroids for at least three months but are permissible if the child is on alternate day steroids $(<0.5$ $\mathrm{mg} / \mathrm{kg} /$ body weight/day).

1 Watson AR. Nephrotic syndrome. In: Campbell AGM, McIntosh N, eds. Forfar and Arneil's textbook of paediatrics. Edinburgh: Churchill Livingstone, 1992: 1057-61. 